\title{
Comparison of cell profiles in separately evaluated fractions of bronchoalveolar lavage (BAL) fluid in children
}

\author{
P Pohunek, H Pokorná, I Stříž
}

\begin{abstract}
Background-Bronchoalveolar lavage (BAL) has been widely accepted as a routine procedure in the differential diagnosis of respiratory diseases in adults. However, there is only limited information about the value of BAL in children and there is no standardisation of the procedures.

Methods - The difference in cellular profiles of sequential BAL fractions from children was analysed to assess the effect of evaluating bronchial and alveolar fractions separately. Twenty five children (mean age 13.4 years) were examined by fibreoptic bronchoscopy under general anaesthesia, combined with local application of lignocaine. The investigation was part of the clinical evaluation of an infective pulmonary problem. Bronchoalveolar lavage was performed from the right middle lobe using four $20 \mathrm{ml}$ aliquots of normal saline and the four fractions of recovered fluid were evaluated separately.

Results - The total cell count was lowest in the first aspirate $\left(1.8 \times 10^{6}\right)$ and increased gradually from fraction 1 to fraction 4 . Similarly, the viability of the cells was lowest in fraction 1 and gradually improved from fraction 1 to fraction 4 . In the differential count the number of neutrophils decreased from fraction $1(8 \cdot 3 \%)$ to fraction 4 , with fractions $2(5 \cdot 4 \%), 3$ $(3 \cdot 4 \%)$, and $4(2 \cdot 4 \%)$ being significantly different from fraction 1 . There were no differences in the numbers of eosinophils, lymphocytes, or macrophages between individual fractions.

Conclusions - These results show that the cell profile of the first "bronchial" fraction is different from subsequent samples. It should be evaluated separately while the second and third aliquots may be pooled. (Thorax 1996;51:615-618)
\end{abstract}

Keywords: bronchoalveolar lavage, fractional processing, children.

Bronchoalveolar lavage (BAL) has become a widely used procedure in various clinical settings including the differential diagnosis and monitoring of interstitial lung disease, ${ }^{1}$ and for the detection of opportunistic infections in immunocompromised patients. ${ }^{23}$ It has also been frequently applied in research to study bronchial and alveolar pathology.

The availability of paediatric flexible bronchoscopes has extended the usefulness of BAL into paediatric pulmonology. ${ }^{4-8}$ In adults the basic methodological recommendations have been summarised by the BAL Task Group within the European Respiratory Society, ${ }^{910}$ but there is no generally accepted standardisation in children.

Some authors report using the lavage volume related to body weight. Typically, volumes have ranged from 0.75 to $1 \mathrm{ml} / \mathrm{kg}$ per aliquot and the number of aliquots has also varied. ${ }^{11-13}$ Furthermore, the methods of processing the recovered lavage fluid vary. The aspirated fractions of lavage fluid are usually pooled but, to our knowledge, only two groups have looked at the possibility of fractional processing of BAL fluid from children to distinguish bronchial from alveolar material. However, one of these studies was performed in intubated newborn infants by a non-bronchoscopic approach, ${ }^{12}$ while the other was performed in healthy children undergoing elective surgery with only the first fraction separated. ${ }^{14}$ In the recently published study by Midulla et al the authors analysed the cellular and non-cellular components of BAL fluid in small children using only the second fraction whilst the first fraction was used for microbiological analysis. ${ }^{15}$

We have therefore assessed the differences in cytological findings in sequential fractions of BAL fluid in order to resolve the difficulties in the application and evaluation of BAL in children.

\section{Methods}

STUDY SUBJECTS

The study subjects comprised 24 patients of mean (SD) age $13.5(2 \cdot 7)$ years (range 8-18) and mean (SD) weight $40 \cdot 1(14 \cdot 6) \mathrm{kg}$ (range 25-80) who were undergoing bronchoscopic examination with BAL for investigation of clinical symptoms. The clinical diagnoses of the subjects were recurrent productive cough (14), chronic productive cough (5), chronic dry cough (4), and recurrent pneumonia (1).

Informed parental consent was obtained for each child to participate in the study.

\section{BRONCHOSCOPY}

All of the children were examined with a Pentax FB 15X bronchoscope (outer diameter $4.9 \mathrm{~mm}$ and $2.2 \mathrm{~mm}$ working channel) while spontaneously breathing under ketamine general anaesthesia combined with the topical application of $1 \%$ or $2 \%$ lignocaine. No muscle relaxing drugs were used. Pulse rate, ECG, and 
oxygen saturation were monitored during the procedure and for at least 30 minutes afterwards. After the routine examination the bronchoscope was wedged either into the right middle lobe bronchus or into one of the segmental bronchi.

BRONCHOALVEOLAR LAVAGE (BAL)

BAL was performed using four $20 \mathrm{ml}$ aliquots of normal saline warmed to $37^{\circ} \mathrm{C}$. The fluid was injected through the channel of the bronchoscope and each fraction was immediately gently aspirated back by the same syringe. Each aspirate was immediately transferred from the syringe into a plastic vial, labelled, and stored separately for evaluation.

PROCESSING OF BAL FLUID

Each fraction of BAL fluid was filtered through two layers of gauze and the recovered fluid was centrifuged separately $(10$ minutes at $1700 \mathrm{~g}$ ). The cells were then counted in a haemacytometer. Air dried smears were stained with May-Grunwald-Giemsa stain for differential cell counts. At least 300 cells were counted, excluding epithelial cells. The viability of the cells was determined by trypan-blue exclusion and the phagocytic activity by the ingestion of synthetic methacrylate particles.

\section{DATA ANALYSIS}

For the statistical analysis Friedman two-way ANOVA was used. Post-hoc significances of differences were determined by the Nemenyi method. A p value of $<0.05$ was considered significant.

\section{Results}

The total and differential cell counts, viability of cells, and phagocytosis of alveolar macrophages are shown in the table.

TOTAL NUMBER AND VIABILITY OF BAL CELLS The total cell count was lowest in the first aspirate $\left(1.8 \times 10^{6}\right)$ and increased gradually from fraction 1 to fraction 4 up to a value of $3.6 \times 10^{6}$ (fig 1). Statistical significance $(\mathrm{p}<0.01)$ was reached between the first and second aspirates and increased with further samples $(p<0.001)$. Similarly, the viability of the cells was lowest in fraction 1 and gradually improved with each fraction (fig 2), the differ-

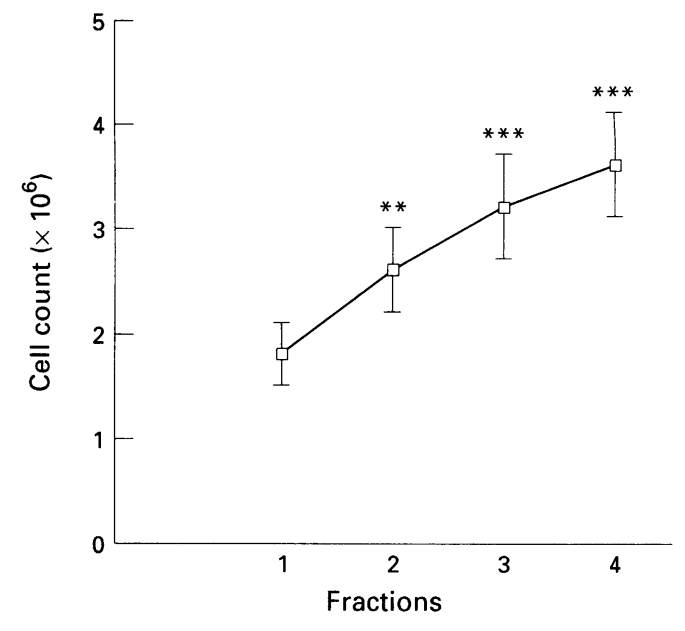

Figure 1 Total cell count. ${ }^{* *} p<0 \cdot 01 ;{ }^{* * *} p<0 \cdot 001$.

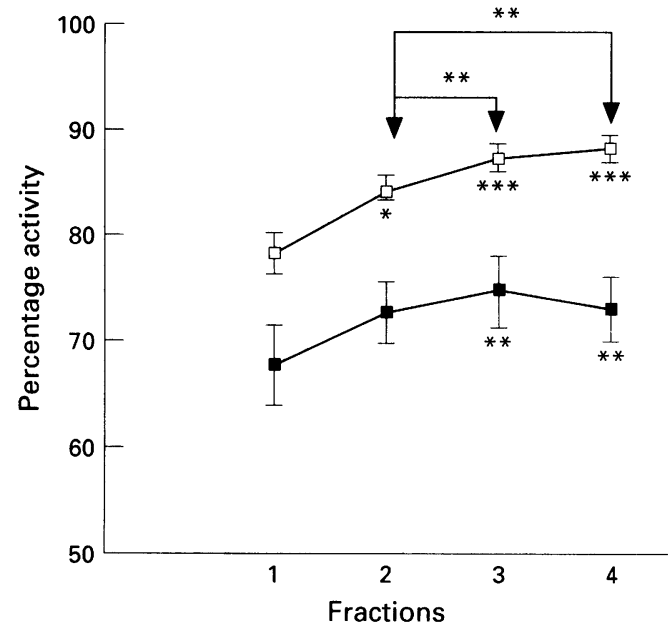

Figure 2 Percentage viability $(\square)$ and phagocytic activity. ${ }^{*} p<0 \cdot 05 ;{ }^{* *} p<0 \cdot 01 ;{ }^{* * *} p<0 \cdot 001$.

ence becoming significant in fractions 2 $(p<0.05), 3(p<0.001)$, and $4(p<0.001)$.

\section{DIFFERENTIAL COUNT OF FRACTIONATED BAL} CELLS

The most striking difference in the differential cell count between individual aliquots was the percentage of neutrophils (fig 3). The highest number of neutrophils was found in fraction $1(8.3 \%)$ and the percentage decreased from fraction 1 to 4 , with fractions $2(5 \cdot 4 \%), 3$

Mean (SE) results of analysis of sequential fractions of BAL fluid

\begin{tabular}{|c|c|c|c|c|c|}
\hline & \multicolumn{4}{|l|}{ Fraction } & \\
\hline & 1 & 2 & 3 & 4 & \\
\hline $\begin{array}{l}\text { Cell count }\left(\times 10^{6}\right) \\
\text { Viability }(\%)\end{array}$ & $\begin{array}{r}1 \cdot 8(0 \cdot 3) \\
78 \cdot 3(2 \cdot 0)\end{array}$ & $\begin{array}{l}2 \cdot 6(0 \cdot 4)^{* *} \\
84 \cdot 1(1 \cdot 6)^{*}\end{array}$ & $\begin{array}{r}3 \cdot 2(0 \cdot 5)^{* * *} \\
87 \cdot 4(1 \cdot 3)^{* * *}\end{array}$ & $\begin{array}{r}3 \cdot 6(0 \cdot 5)^{* * *} \\
88 \cdot 3(1 \cdot 3)^{* * *}\end{array}$ & $\begin{array}{l}{[2-3 * *]} \\
{[2-4 * *]}\end{array}$ \\
\hline $\begin{array}{l}\text { Phagocytosis (\%) } \\
\text { Macrophages (\%) } \\
\text { Neutrophils }(\%) \\
\text { Lymphocytes }(\%) \\
\text { Eosinophils }(\%)\end{array}$ & $\begin{array}{r}67 \cdot 7(3 \cdot 8) \\
77 \cdot 1(2 \cdot 9) \\
8 \cdot 3(1 \cdot 9) \\
13 \cdot 3(1 \cdot 9) \\
1.4(0 \cdot 6)\end{array}$ & $\begin{array}{l}72.7(2.9) \\
78.7(2.5) \\
5.4(1.7)^{* *} \\
14.5(1.9) \\
1.4(0.4)\end{array}$ & $\begin{array}{c}74 \cdot 6(3 \cdot 4)^{* *} \\
82 \cdot 0(3 \cdot 0) \\
3 \cdot 4(1 \cdot 7)^{* * *} \\
14 \cdot 0(2 \cdot 2) \\
0 \cdot 6(0 \cdot 2)\end{array}$ & $\begin{array}{c}72.9(3 \cdot 1)^{* *} \\
83 \cdot 3(2 \cdot 5) \\
2 \cdot 4(0 \cdot 9)^{* * *} \\
13.5(2 \cdot 1) \\
0.6(0 \cdot 2)\end{array}$ & {$\left[2-4^{*}\right]$} \\
\hline
\end{tabular}

${ }^{*} \mathrm{p}<0.05 ;{ }^{* *} \mathrm{p}<0.01 ;{ }^{* * *} \mathrm{p}<0.001$. 


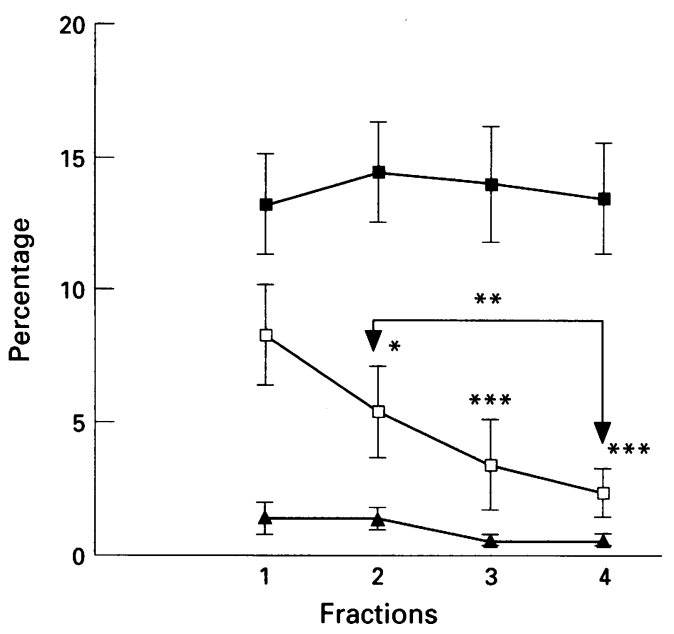

Figure 3 Percentage of neutrophils ( $\square$ ), lymphocytes ( $)$, and eosinophils ( $\mathbf{\Delta}$ ) in bronchoalveolar fluid. $* p<0.05 ; * * p<0.01 ; * * * p<0.001$.

$(3 \cdot 4 \%)$, and $4(2 \cdot 4 \%)$ being significantly different from fraction $1(\mathrm{p}<0.01, \mathrm{p}<0.001$, and $p<0.001$, respectively). There were no significant differences in the numbers of eosinophils, lymphocytes, and macrophages between individual fractions.

\section{PHAGOCYTIC ACTIVITY OF ALVEOLAR}

MACROPHAGES

The ingestion of methacrylate particles by alveolar macrophages ranged from $28 \%$ to $94 \%$. Analysis of the phagocytic activity of the alveolar macrophages only became significant between fractions $1(67 \cdot 7 \%)$ and $3(74 \cdot 6 \%)$ $(\mathrm{p}<0.01)$, and fractions 1 and $4(72.9 \%)$ $(\mathrm{p}<0.01)$.

Comparisons of fractions 2,3 , and 4 did not reveal any significant differences with the exception of the viability of the cells between fractions 2 and $3(p<0.01)$, and between fractions 2 and $4(p<0 \cdot 01)$. A significant difference was also found in the percentage of neutrophils between fractions 2 and $4(p<0 \cdot 05)$.

\section{COMPLICATIONS}

The only complication encountered was a short febrile reaction with pleurisy in one patient which occurred six hours after the procedure and subsided after a single dose of $500 \mathrm{mg}$ paracetamol.

\section{Discussion}

Our study has shown that BAL, using $20 \mathrm{ml}$ aliquots of saline and performed as part of a diagnostic bronchoscopic examination, is well tolerated in school age children and provides sufficient cell numbers for analysis. The first fraction of BAL fluid differed significantly from the subsequent samples, particularly in the lower number and viability of recovered cells, and the increased percentage of neutrophils. In contrast to recent studies of the differential cytology of BAL fluid in normal children, ${ }^{14}$ no change in the proportion of lymphocytes was found, and the percentage of granulocytes was higher in our patients than in normal subjects. This reflected the disease groups studied.

Detailed fractional analysis of BAL fluid in adults ${ }^{16}$ using five $20 \mathrm{ml}$ aliquots showed that the first fraction was significantly enriched by bronchial cellular material with an increased presence of bronchial epithelial cells, neutrophils, lactoferrin, lysozyme, and IgA. Similar results were also found in adult patients with sarcoidosis and with bronchial asthma, showing differences in cellular findings in the first ("bronchial") and subsequent fractions. ${ }^{17-19}$ It has been recommended therefore that the first fraction of BAL fluid should be processed separately, especially when the pathology of the bronchi is being considered. ${ }^{16}$

The differential count has been a widely used parameter in the routine investigation of inflammatory disorders in the lungs. From available data it is obvious that a pooled BAL specimen contains both airway and alveolar cells, and inflammation in either anatomical compartment leads to changes in the pooled BAL fluid. Separation of the first portion of the aspirated fluid could thus improve the information gained and could be adopted for routine protocols when bronchial disease is suspected.

As no significant differences were found between the second, third, and fourth aliquots, we conclude that separation of further aliquots would be of no further value.

BAL has been widely used in the paediatric age group for diagnostic and research purposes, but no standard values are available. The volumes used vary substantially with aliquots of $0 \cdot 75-1 \mathrm{ml} / \mathrm{kg}$ often being given to small children, while in older children aliquots of $10-20 \mathrm{ml}$ have been common. ${ }^{520}$ In our study we have used volumes of $20 \mathrm{ml}$ for all children, mainly for technical reasons, which resulted in volumes of $0.25-0.80 \mathrm{ml} / \mathrm{kg}$ per aliquot. Despite this wide range, the cellular analysis was always satisfactory and the range of volume did not have any influence on the reliability of the results. This correlates with recently published results in normal children. ${ }^{15}$ Our data prove that, even in the separated first "bronchial" fraction, the number of cells was satisfactory and enabled reliable analysis of the differential count. The volume of $20 \mathrm{ml}$ per aliquot used in this study seems to be sufficient for proper sampling of both the bronchial and alveolar compartments. With subsequent aliquots the differences in individual fractions diminished, indicating that the later lavage fluid apparently sampled primarily the alveolar space. Our results are in agreement with those of Rennard et $a l^{16}$ who used an aliquot volume for adults of $20 \mathrm{ml}$. The volume infused was independent of body weight and thus was lower per kg body weight than in our patients without any effect on cellular analysis. Volumes larger than $20 \mathrm{ml}$ are less reliable for the separation of the bronchial and alveolar samples.

The authors wish to express their thanks to Dr Austin B Thompson for kind reviewing of the manuscript.

1 Daniele RP, Elias JA, Epstein PE, Rossman MD. Bronchoalveolar lavage: role in the pathogenesis, diagnosis and 
management of interstitial lung disease. Ann Intern Med 1985;102:93-108.

2 Glaser JH, Schuval S, Burstein O, Bye MR. Cytomegalovirus and Pneumocystis carinii pneumonia in children with acquired immunodeficiency syndrome. I Pediatr 1992; 120:929-31.

3 Abadco DL, Amaro-Galvez R, Rao M, Steiner P. Experience with flexible fiberoptic bronchoscopy with bronchoalveolar lavage as a diagnostic tool in children with AIDS. $A m \mathcal{F}$ Dis Child 1992;146:1056-9.

4 Kurland G, Noyes BE, Jaffe R, Atlas AB, Armitage J, Orenstein DM. Bronchoalveolar lavage and transbronchial biopsy in children following heart-lung and lung transplantation. Chest 1993;104:1043-8.

5 McCubbin MM, Trigg ME, Hendricker CM, Wagener JS. Bronchoscopy with bronchoalveolar lavage in the evaluation of pulmonary complications of bone marrow transplantation in children. Pediatr Pulmonol 1992;12:43-7.

plantation in children. Pediatr Pulmonol 1992;12:43-7.
6 Murphy S, Kelly HW. Asthma, inflammation, and airway hyperresponsiveness in children. Curr Opin Pediat 1993; 5:255-65.

7 Wilmott RW, Kassab JT, Kilian PL, Benjamin WR, Douglas SD, Wood RE. Increased levels of interleukin-1 in $\mathrm{SD}$, Wood RE. Increased levels of interleukin-1 in
bronchoalveolar washings from children with bacterial bronchoalveolar washings from children with bacterial
pulmonary infections. Am Rev Respir Dis 1990;142:365-8.

pulmonary infections. Am Rev Respir Dis 1990;142:365-8.
8 Winthrop AL, Waddell T, Superina RA. The diagnosis of pneumonia in the immunocompromised child: use of bronchoalveolar lavage. $\mathcal{F}$ Pediatr Surg 1990;25:878-80.

$9 \mathrm{Klech} \mathrm{H}$, Hutter $\mathrm{C}$, eds. Clinical guidelines and indications for bronchoalveolar lavage. Eur Respir f 1990;3:937-74.

$10 \mathrm{Klech} \mathrm{H}$, Pohl W, eds. Technical recomendations and guidelines for bronchoalveolar lavage (BAL). Eur Respir f 1989; 2:561-85.

11 Grigg J, Arnon S, Silverman M. Fractional processing of sequential bronchoalveolar lavage fluid from intubated babies. Eur Respir f 1992;5:727-32.
12 Alpert BE, O'Sullivan BP, Panitch HB. Nonbronchoscopic approach to bronchoalveolar lavage in children with artiapproach to bronchoalveolar lavage in children

13 Amaro-Galvez R, Rao M, Abadco D, Kravath RE, Steiner P. Nonbronchoscopic bronchoalveolar lavage in ventilated children with acquired immunodeficiency syndrome: a simple and effective diagnostic method for Pneumocystis carinii infection. Pediatr Infect Dis $\mathcal{F}$ 1991;10:473-5.

14 Ratjen F, Bredendiek M, Brendel M, Meltzert J, Costabel U. Differential cytology of bronchoalveolar lavage fluid in normal children. Eur Respir f 1994;7:1865-70.

15 Midulla F, Villani A, Merolla R, Bjermer L, Sandstrom T, Ronchetti R. Bronchoalveolar lavage studies in children without parenchymal lung disease: cellular constituents without parenchymal lung disease: cellular constituen

16 Rennard SI, Ghafouri MO, Thompson AB, Linder J, Vaughan W, Jones $\mathrm{K}$, et al. Fractional processing of sequential bronchoalveolar lavage to separate bronchial and alveolar samples. Am Rev Respir Dis 1990;141:208-17.

17 Winterbauer RH, Wu R, Springmeyer SC. Fractional analysis of the $120-\mathrm{ml}$ bronchoalveolar lavage. Determination of the best specimen for diagnosis of sarcoidosis. Chest 1993;104:344-51.

18 Aalbers R, Kauffman HF, Vrugt B, Smith M, Koeter GH, Timens W, et al. Bronchial lavage and bronchoalveolar lavage in allergen-induced single early and dual asthmatic responders. Am Rev Respir Dis 1993;147:76-81.

19 Van Vyve T, Chanez P, Lacoste JY, Bousquet J, Michel FB, Godard P. Comparison between bronchial and alveolar samples of bronchoalveolar lavage fluid in asthma. Chest 1992;102:356-61.

20 Whitehead B, Scott JP, Helms P, Malone M, Macrae D, Higenbottam TW, et al. Technique and use of transbronchial biopsy in children and adolescents. Pediatr Pulmonol 1992;12:240-6. 